\title{
ANALISA AKTIVITAS PENGANGKATAN DENGAN METODE RECOMMENDED WEIGHT LIMIT (RWL)
}

\author{
Ratna Ayu Ratriwardhani \\ Program Studi D-IV Keselamatan dan Kesehatan Kerja \\ Fakultas Kesehatan, Universitas Nahdlatul Ulama Surabaya \\ Email: ratna.ayu@unusa.ac.id
}

\begin{abstract}
Manual material handling if done inappropriately can pose a risk of injury to the body, mainly in the spine, which is usually referred as musculoskeletal disorders (MSDs). Based on direct interview with warehouse workers of PT. X, it is known that in the lifting or transfering mineral water activity often causes pain in the waist and spine. This study is intended to analyze the work posture and the load level that is safe for workers to reduce the risk of MSDs, the analysis is carried out with the Recommended Weight Limit (RWL) method. From the calculation gained RWL origin $=15.36 \mathrm{~kg} / 34.07 \mathrm{lbs}$ and destination $R W L=18.54 \mathrm{~kg} / 41.12 \mathrm{lbs}$. Then the origin LI value $=$ 0.9 and destination $L I=0.8$. From the results of the Lifting Index can be concluded that the risk level of this work is low and there is no problem with the lifting work. The weight of load raised does not exceed the recommended lifting limit, so there are no repairs to the work needed, but the activity must keep to get attention so the LI value can be maintained and the activity does not bear the risk of spinal injury.
\end{abstract}

Keywords: RWL, Lifting Index, NIOSH Lifting Equation

\begin{abstract}
ABSTRAK
Pengangkatan benda secara manual jika dilakukan dengan cara yang salah dapat menyebabkan cidera, terutama cidera pada tulang belakang. Seperti gangguan di bagian otot skeletal yang dapat diakibatkan karena beban yang diterima otot secara terus-menerus dalam kurun waktu yang cukup lama. Keluhan seperti ini biasa disebut dengan musculoskeletal disorders (MSDs). Berdasarkan wawancara secara langsung kepada para pekerja gudang di PT. X ini, diketahui bahwa pada aktivitas pengangkatan atau pemindahan dus air mineral kerapkali menyebabkan nyeri pada tulang belakang dan juga pinggang para pekerja. Penelitian ini bertujuan untuk menganalisis posisi kerja dan untuk mengetahui berapa berat beban yang aman bagi pekerja sehingga terhindar dari resiko penyakit MSDs. Analisis dilakukan dengan metode Recommended Weight Limit (RWL). Dari perhitungan didapatkan nilai RWL origin $=15,36 \mathrm{~kg} / 34,07 \mathrm{lbs}$ dan nilai RWL destination $=18,54 \mathrm{~kg} / 41,12 \mathrm{lbs}$. Kemudian nilai LI origin $=0,9$ dan LI destination $=0,8$. Dari hasil Lifting Index tersebut dapat disimpulkan bahwa tingkat resiko pekerjaan ini rendah, pada pekerjaan ini tidak ada masalah dengan pekerjaan angkat-angkut. Berat dus air mineral yang diangkat oleh pekerja tidak melebihi RWL, sehingga tidak diperlukan perbaikan terhadap pekerjaan, tetapi harus terus mendapatkan perhatian agar nilai LInya dapat tetap dipertahankan sehingga aktivitas tersebut tidak mengandung resiko cedera tulang belakang.
\end{abstract}

Kata kunci: RWL, Lifting Index, NIOSH Lifting Equation 


\section{PENDAHULUAN}

Pengangkatan benda secara manual jika dilakukan dengan cara yang salah dapat menyebabkan cidera, terutama cidera pada tulang belakang. Seperti gangguan di bagian otot skeletal yang dapat diakibatkan karena beban yang diterima otot secara terus-menerus dalam kurun waktu yang cukup lama. Keluhan seperti ini biasa disebut dengan musculoskeletal disorders (MSDs).

Kecelakaan yang ada di industri yang diakibatkan karena pengangkatan beban yang berlebih disebut "over exertion lifting and carrying" atau kerusakan jaringan tubuh yang disebabkan karena beban angkat yang berlebihan. ${ }^{1}$ Menurut data terkait konpensasi pekerja di negara bagian New South Wales Australia, ${ }^{1}$ data mengenai kecelakaan yang diakibatkan oleh hal tersebut mencapai angka $18 \%$ dari seluruh kecelakaan yang ada di industri selama tahun 1982-1985. Dari data kecelakaan itu, 93\% diantaranya disebabkan karena strain atau rasa nyeri yang berlebihan, sedangkan 5\% lainnya karena hernia. Dari data tentang strain, $61 \%$ diantaranya berada di bagian punggung. Dari hasil penelitian yang dilakukan oleh NIOSH (The National Institute of Occupational Safety and Health), ${ }^{2}$ dapat dilihat bahwa tingginya angka kecelakaan kerja kebanyakan disebabkan karena kecerobohan dan keteledoran dari pekerja itu sendiri, seperti yang terjadi pada proses pengangkatan benda secara manual, pengangkatan dilakukan secara tidak ergonomis. Pekerjaan pengangkatan benda secara manual biasa dilakukan dengan cara menarik (pull), mendorong (push), membawa (carry), dan mengangkat yang dapat dilakukan dengan cara menaikan barang (loading) atau menurunkan barang (unloading).

Masalah MSDs sering ditemui pada pekerjaan yang dilakukan secara manual, seperti pekerjaan angkat-angkut. Berdasarkan wawancara secara langsung kepada para pekerja gudang di PT. X ini, diketahui bahwa pada aktivitas pengangkatan atau pemindahan dus air mineral kerapkali menyebabkan nyeri pada tulang belakang dan juga pinggang para pekerja. Hal itu terjadi dikarenakan pekerjaan ini dilakukan secara terus-menerus dengan membawa beban yang cukup berat.

Berdasarkan masalah yang telah disebutkan diatas, maka penelitian ini bertujuan untuk menganalisis posisi kerja dan untuk mengetahui berapa berat beban yang aman bagi pekerja sehingga terhindar dari resiko penyakit MSDs. Analisis dilakukan dengan metode Recommended Weight Limit (RWL).

\section{METODE PENELITIAN}

Penelitian ini merupakan penelitian yang bersifat deskriptif. Penelitian ini dilakukan secara observasional dengan melakukan pengamatan pada kondisi lingkungan tanpa memberikan perlakuan kepada responden.

Pada penelitian ini metode yang digunakan adalah Recommended Weight Limit 
(RWL). RWL adalah berat beban yang masih aman untuk dikerjakan oleh pekerja dalam waktu tertentu tanpa meningkatkan resiko gangguan sakit pinggang (low back pain). ${ }^{3}$

Pada tahun 1991 RWL direkomendasikan oleh NIOSH di Amerika Serikat. RWL untuk aktivitas pengangkatan yang memenuhi syaratsyarat berikut: $^{2}$

a. Beban statis.

b. Beban diangkat atau diturunkan oleh kedua tangan.

c. Pengangkatan atau penurunan benda dilakukan dalam waktu maksimal 8 jam.

a. Pengangkatan atau penurunan benda tidak boleh dilakukan saat duduk atau berlutut.

b. Tempat kerja tidak sempit.

RWL dihitung berdasarkan enam variabel seperti yang terlihat pada Gambar 1 dan 2 dibawah ini.

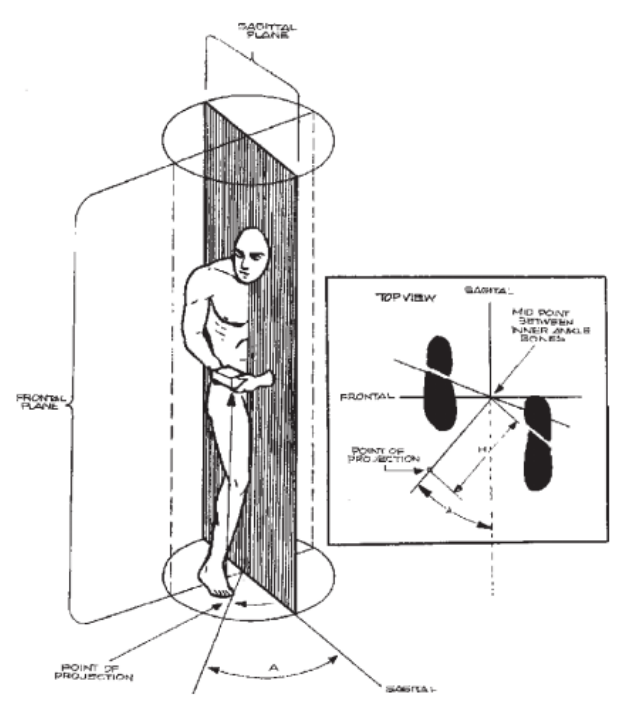

Gambar 1. Ilustrasi Sudut Putar pada Saat Memindahkan Beban. ${ }^{3}$

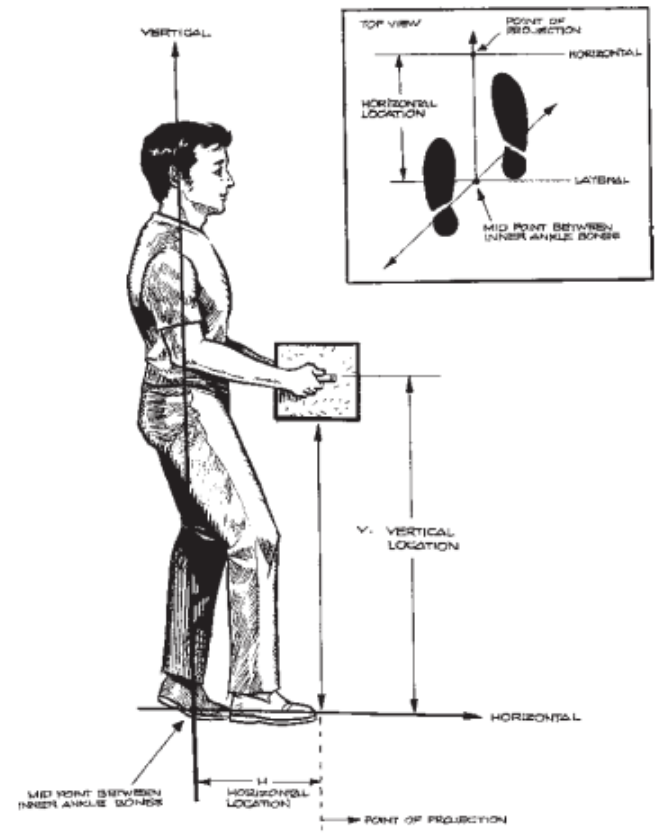

Gambar 2. Ilustrasi Posisi Tangan pada Saat Mengangkat Beban. ${ }^{3}$

Keterangan Gambar:

$\mathrm{H}$ = Jarak horizontal antara beban dengan pekerja (Horizontal location)

$\mathrm{V}=$ Jarak vertikal antara lantai dengan pegangan (Vertical location)

$\mathrm{D}=$ Jarak lintasan dari tempat awal ke tempat yang dituju (Destination)

$\mathrm{A}=$ Sudut putar pada saat memindahkan beban (Angle of Asymetric)

$\mathrm{F}=$ Frekuensi dan durasi dari pengangkatan (Frequency of lifting)

$\mathrm{C}=$ Klasifikasi pegangan tangan (Coupling classification)

Persamaan untuk menentukan beban yang direkomendasikan untuk diangkat seorang pekerja dalam kondisi tertentu menurut NIOSH adalahsebagai berikut: ${ }^{4}$

$R W L=L C \times H M \times V M \times D M \times A M \times F M \times C M$ 
Di mana:

$$
\begin{aligned}
\mathrm{LC}= & \text { Load Constant (konstanta pembebanan) } \\
= & 23 \mathrm{~kg} / 51 \mathrm{lbs} \\
\mathrm{HM}= & \text { Horizontal Multiplier (faktor pengali } \\
& \text { horizontal) } \\
\mathrm{VM}= & \text { Vertical Multiplier (faktor pengali } \\
& \text { vertikal) } \\
\mathrm{DM}= & \text { Distance Multiplier (faktor pengali } \\
& \text { perpindahan) } \\
\mathrm{AM}= & \text { Asymetric Multiplier (faktor pengali } \\
& \text { asimentrik) } \\
\mathrm{FM}= & \text { Frequency Multiplier (faktor pengali } \\
& \text { frekuensi) } \\
\mathrm{CM}= & \text { Coupling Multiplier (faktor pengali } \\
& \text { kopling atau handle) }
\end{aligned}
$$

Nilai FM ditentukan dari Tabel 1 disamping ini. ${ }^{5}$
Tabel 1. Frequency Multipler

\begin{tabular}{|c|c|c|c|c|c|c|}
\hline \multirow{2}{*}{$\begin{array}{c}\text { Frequency } \\
\text { Lifts/min }\end{array}$} & \multicolumn{6}{|c|}{ Lama Kerja Mengangkat } \\
\cline { 2 - 7 }$(\mathrm{F})$ & \multicolumn{2}{|c|}{$\leq 1 \mathrm{jam}$} & \multicolumn{2}{c|}{$>1$ dan $\leq 2$ jam } & \multicolumn{2}{c|}{$>2$ dan $\leq 8 \mathrm{jam}$} \\
\cline { 2 - 7 } & $\mathrm{V}^{\mathrm{b}}<75$ & $\mathrm{~V}>75$ & $\mathrm{~V}<75$ & $\mathrm{~V} \geq 75$ & $\mathrm{~V}<75$ & $\mathrm{~V} \geq 75$ \\
\hline \multirow{2}{*}{0,2} & 1,00 & 1,00 & 0,95 & 0,95 & 0,85 & 0,85 \\
0,5 & 0,97 & 0,97 & 0,92 & 0,92 & 0,81 & 0,81 \\
1 & 0,94 & 0,94 & 0,88 & 0,88 & 0,75 & 0,75 \\
2 & 0,91 & 0,91 & 0,84 & 0,84 & 0,65 & 0,65 \\
3 & 0,88 & 0,88 & 0,79 & 0,79 & 0,55 & 0,55 \\
4 & 0,84 & 0,84 & 0,72 & 0,72 & 0,45 & 0,45 \\
5 & 0,80 & 0,80 & 0,60 & 0,60 & 0,35 & 0,35 \\
6 & 0,75 & 0,75 & 0,50 & 0,50 & 0,27 & 0,27 \\
7 & 0,70 & 0,70 & 0,42 & 0,42 & 0,22 & 0,22 \\
8 & 0,60 & 0,60 & 0,35 & 0,35 & 0,18 & 0,18 \\
9 & 0,52 & 0,52 & 0,26 & 0,26 & 0,00 & 0,15 \\
10 & 0,45 & 0,45 & 0,00 & 0,23 & 0,00 & 0,13 \\
11 & 0,41 & 0,41 & 0,00 & 0,21 & 0,00 & 0,00 \\
12 & 0,37 & 0,37 & 0,00 & 0,00 & 0,00 & 0,00 \\
13 & 0,00 & 0,34 & 0,00 & 0,00 & 0,00 & 0,00 \\
14 & 0,00 & 0,31 & 0,00 & 0,00 & 0,00 & 0,00 \\
15 & 0,00 & 0,28 & 0,00 & 0,00 & 0,00 & 0,00 \\
$>15$ & 0,00 & 0,00 & 0,00 & 0,00 & 0,00 & 0,00 \\
& & & & & & \\
\hline
\end{tabular}

${ }^{a}$ untuk frequency angkatan kurang dari sekali per 5 menit, $\mathrm{F}=0,2 \mathrm{lift} / \mathrm{min}$. ${ }^{\mathrm{b}}$ diekspresikan dalam $\mathrm{cm}$ dan diukur dari permukaan lantai.

Klasifikasi pegangan tangan dikategorikan kedalam tiga kategori yaitu Bagus, Sedang, dan Jelek. Ketiga kategori tersebut dijelaskan seperti pada Tabel 2 di bawah ini. ${ }^{6}$

Tabel 2. Klasifikasi Kopling (Tangan ke Kontainer)

\begin{tabular}{llll}
\hline \multicolumn{1}{c}{ BAGUS $(G O O D)$} & \multicolumn{2}{c}{ SEDANG $(F A I R)$} & \multicolumn{1}{c}{ JELEK $(P O O R)$} \\
\hline $\begin{array}{l}\text { Kontainer dengan desain optimal, } \\
\text { seperti: box, peti kayu, dll. }\end{array}$ & $\begin{array}{l}\text { Kontainer } \\
\text { optimal }\end{array}$ & dengan desain & $\begin{array}{l}\text { Kontainer dengan desain kurang } \\
\text { optimal atau objek yang tidak } \\
\text { beraturan, berukuran sangat besar, } \\
\text { sulit untuk dipegang, pinggirnya }\end{array}$ \\
& & runcing, dan licin, dll.
\end{tabular}

\begin{tabular}{ll}
\hline Untuk objek yang tidak beraturan, & Untuk kontainer dengan desain \\
yang tidak dikemas dalam & optimal tapi tidak ada pegangan \\
container. Kategori "Bagus" & atau objek tidak beraturan. \\
dijelaskan sebagai suatu pegangan & Kategori "Sedang" dijelaskan \\
yang nyaman, yang mana tangan & sebagai suatu pegangan yang \\
dapat dengan mudah memegang & mana tangan dapat ditekuk \\
permukaan objek & dengan sudut sekitar $90^{\circ}$
\end{tabular}

Berdasarkan klasifikasi kopling dan Tabel 3. Coupling Multipler lokasi mengangkat vertical, Coupling Multiplier (CM) dapat ditentukan dari Tabel 3 disamping ini. ${ }^{5}$

\begin{tabular}{|l|c|c|}
\hline \multirow{2}{*}{ Tipe Coupling } & \multicolumn{2}{|c|}{ CM } \\
\cline { 2 - 3 } & $\mathrm{V}<75 \mathrm{~cm}$ & $\mathrm{~V} \geq 75 \mathrm{~cm}$ \\
\hline Baik (Good) & 1,00 & 1,00 \\
Sedang (Fair) & 0,95 & 1,00 \\
Jelek (Poor) & 0,90 & 0,90 \\
\hline
\end{tabular}


Jika perhitungan RWL telah dilakukan, langkah selanjutnya dilakukan perhitungan LI. LI atau Lifting Index adalah perhitungan sederhana terkait resiko cidera yang dapat diakibatkan karena pengangkatan beban. LI ini dapat dihitung dengan rumus sebagai berikut:

$$
\mathrm{LI}=\frac{\text { Berat Beban }}{R W L}
$$

Hasil perhitungan nilai LI dapat diklasifikasikan berdasarkan tingkat resiko cedera di bawah ini. ${ }^{5}$

Tabel 4. Klasifikasi Tingkat Risiko Terhadap Nilai LI

\begin{tabular}{|c|c|l|}
\hline $\begin{array}{c}\text { Nilai } \\
\text { LI }\end{array}$ & $\begin{array}{c}\text { Tingkat } \\
\text { Risiko }\end{array}$ & \multicolumn{1}{c|}{ Deskripsi Perbaikan } \\
\hline$<1$ & Rendah & $\begin{array}{l}\text { Tidak adanya masalah dengan pekerjaan mengangkat, maka tidak } \\
\text { diperlukan perbaikan terhadap pekerjaan, tetapi tetap terus } \\
\text { mendapatkan perhatian sehingga nilai LI dapat dipertahankan }<1\end{array}$ \\
\hline $1-<3$ & Sedang & $\begin{array}{l}\text { Ada beberapa parameter angkat, sehingga perlu dilakukan } \\
\text { pengecekan dan redesain segera pada parameter yang menyebabkan } \\
\text { nilai RWL tinggi. Upayakan perbaikan sehingga nilai RWL }<1 .\end{array}$ \\
\hline 3 & Tinggi & $\begin{array}{l}\text { Terdapat banyak permasalahan dari parameter angkat sehingga } \\
\text { diperlukan pengecekan dan perbaikan sesegera mungkin secara } \\
\text { menyeluruh terhadap parameter-parameter yang menyebabkan nilai } \\
\text { tinggi. Upayakan perbaikan sehingga nilai RWL }<1 .\end{array}$ \\
\hline
\end{tabular}

Apabila nilai LI diatas angka $1(\mathrm{LI}>1)$, hal itu berarti berat benda yang diangkat oleh pekerja telah melampaui batas pengangkatan yang direkomendasikan oleh NIOSH dan pekerjaan itu berarti beresiko cedera. Disarankan untuk dilakukan perbaikan dalam posisi kerja dan penurunan berat beban yang diangkat. Apabila nilai LI dibwah angka 1 (LI $<1$ ), hal itu berarti berat benda yang diangkat oleh pekerja tidak melampaui batas pengangkatan yang direkomendasikan oleh $\mathrm{NIOSH}$ dan pekerjaan itu berarti tidak beresiko cedera. ${ }^{4}$

\section{HASIL DAN PEMBAHASAN}

Gambar dibawah ini menunjukan posisi pengangkatan dari asal benda itu berada (origin). Dari gambar tersebut kita ukur nilai $\mathrm{H}$ dan Vnya, sehingga didapatkan nilai $\mathrm{H}$ origin dan nilai V origin. Pada perhitungan ini kita gunakan satuan $\mathrm{cm}$ kemudian dikonversi kedalam satuan inch. Dari hasil perhitungan diketahui nilai $\mathrm{H}$ origin $=20 \mathrm{~cm} / 8$ inch dan nilai $\mathrm{V}$ origin $=5 \mathrm{~cm} / 2 \mathrm{inch}$.

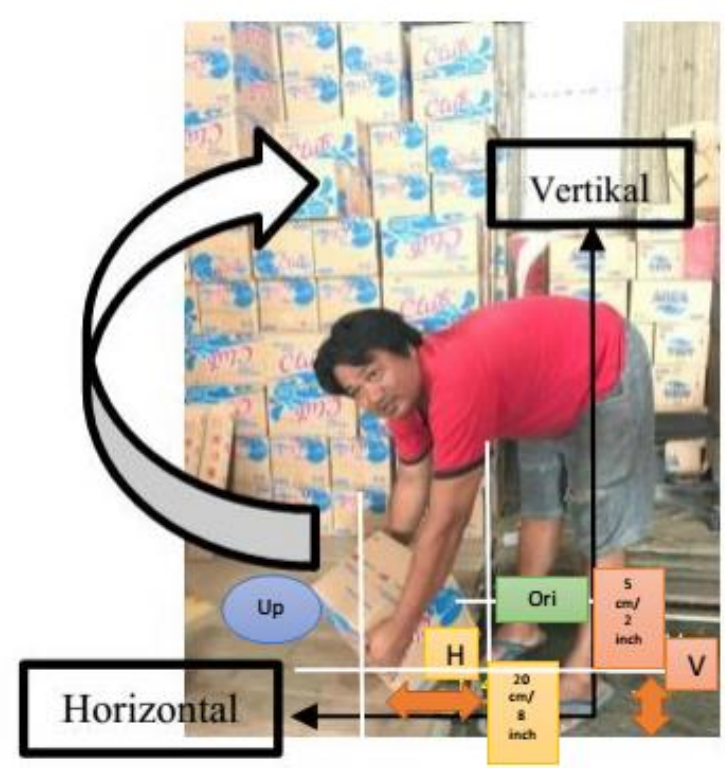

Gambar 3. Posisi pengangkatan (Origin)

Gambar dibawah ini menunjukan posisi pengangkatan tujuan benda itu dipindahkan (destination). Dari gambar tersebut kita ukur nilai $\mathrm{H}$ dan Vnya, sehingga didapatkan nilai $\mathrm{H}$ destination dan nilai $\mathrm{V}$ destination. Pada perhitungan ini kita gunakan satuan $\mathrm{cm}$ kemudian dikonversi kedalam satuan inch. Dari hasil perhitungan diketahui nilai destination $=$ $18 \mathrm{~cm} / 7$ inch dan nilai destination = $70 \mathrm{~cm} / 28 \mathrm{inch}$. 


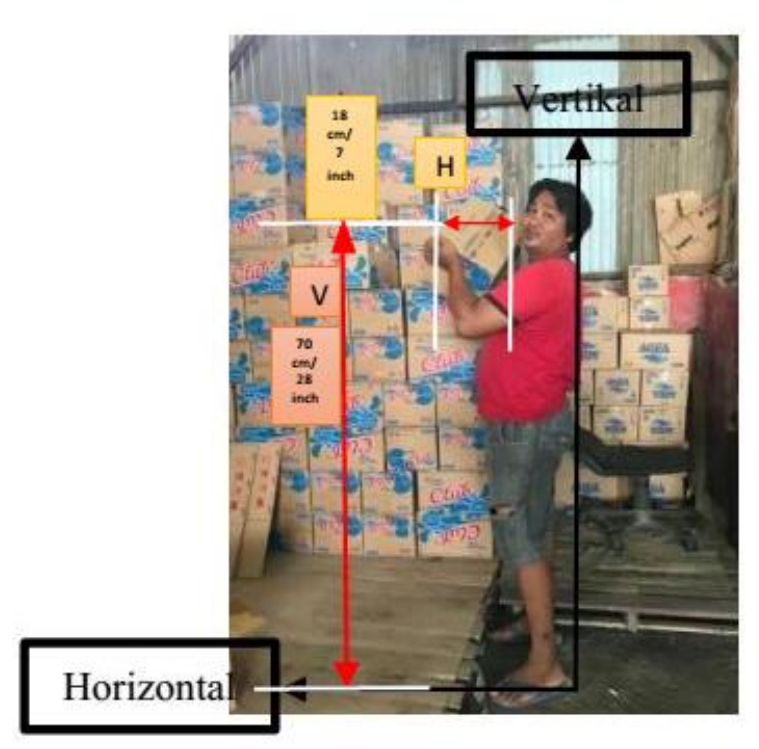

Gambar 4. Posisi pengangkatan (Destination)

Cara menghitung dan hasil dari nilai RWL dan LI dijelaskan secara detail pada Tabel 5 dibawah ini.

Tabel 5. Detail Perhitungan RWL dan LI

\begin{tabular}{|c|c|c|}
\hline & Origin & Destination \\
\hline $\mathbf{L C}$ & $23 \mathrm{~kg} / 51 \mathrm{lbs}$ & $23 \mathrm{~kg} / 51 \mathrm{lbs}$ \\
\hline $\mathbf{H}$ & $20 \mathrm{~cm} / 8$ inch & $18 \mathrm{~cm} / 7$ inch \\
\hline HM & $\begin{array}{l}\mathbf{c m}-25 / \mathrm{H}= \\
25 / 20=1,25 \\
\text { inch }-10 / \mathrm{H}= \\
10 / 8=1,25\end{array}$ & $\begin{array}{l}\mathbf{c m}-25 / \mathrm{H}= \\
25 / 18=1,4 \\
\text { inch }-10 / \mathrm{H}= \\
10 / 7=1,4\end{array}$ \\
\hline $\mathbf{V}$ & $5 \mathrm{~cm} / 2$ inch & $70 \mathrm{~cm} / 28$ inch \\
\hline $\mathbf{V M}$ & $\begin{array}{l}\mathbf{c m}-(1-(0,003 \mid \mathrm{V}- \\
75 \mid) \quad=\quad(1- \\
(0,003|5-75|)) \quad= \\
0,79 \quad(1- \\
\text { inch } \quad= \\
(0,0075|\mathrm{~V}-30|))= \\
(1-(0,0075|2-30|)) \\
=0,79\end{array}$ & $\begin{array}{l}\mathbf{c m}-(1-(0,003 \mid \mathrm{V}- \\
75 \mid) \quad=\quad(1- \\
(0,003|70-75|))= \\
0,99 \quad(1- \\
\text { inch - } \quad(1- \\
(0,0075|\mathrm{~V}-30|))= \\
(1-(0,0075 \mid 28- \\
30 \mid))=0,99\end{array}$ \\
\hline D & $\begin{array}{l}\text { cm }-V \text { dest-V } \\
\text { ori }=70 \mathrm{~cm}-5 \mathrm{~cm} \\
=65 \mathrm{~cm} \\
\text { inch }-\mathrm{V} \text { dest-V } \\
\text { ori }=28 \mathrm{~cm}-2 \mathrm{~cm} \\
=26 \text { inch }\end{array}$ & $\begin{array}{l}\text { cm }-V \text { dest-V } \\
\text { ori }=70 \mathrm{~cm}-5 \mathrm{~cm} \\
=65 \mathrm{~cm} \\
\text { inch }-\mathrm{V} \text { dest-V } \\
\text { ori }=28 \mathrm{~cm}-2 \mathrm{~cm} \\
=26 \text { inch }\end{array}$ \\
\hline DM & $\begin{array}{ll}\mathbf{c m} & - \\
(0,82+(4,5 / \mathrm{D})) & = \\
(0,82+(4,5 / 65)) & = \\
0,89 & - \\
\text { inch } & \end{array}$ & $\begin{array}{ll}\mathbf{c m} & - \\
(0,82+(4,5 / \mathrm{D})) & = \\
(0,82+(4,5 / 65)) & = \\
0,89 & - \\
\text { inch } & -\end{array}$ \\
\hline
\end{tabular}

\begin{tabular}{|c|c|c|}
\hline & Origin & Destination \\
\hline & $\begin{array}{l}(0,82+(1,8 / \mathrm{D})) \\
=(0,82+(1,8 / 26)) \\
=0,89\end{array}$ & $\begin{array}{l}(0,82+(1,8 / \mathrm{D})) \\
=(0,82+(1,8 / 26)) \\
=0,89\end{array}$ \\
\hline $\mathbf{A}$ & 0 & 45 \\
\hline $\mathbf{A M}$ & $\begin{array}{l}(1-(0,0032 \mathrm{~A}))= \\
(1-(0,0032 \times 0))= \\
1\end{array}$ & $\begin{array}{l}(1-(0,0032 \mathrm{~A}))= \\
(1-(0,0032 \times 45)) \\
=0,86\end{array}$ \\
\hline $\mathbf{F}$ & 5 lifts/min & $5 \mathrm{lifts} / \mathrm{min}$ \\
\hline $\begin{array}{l}\text { Work } \\
\text { Duration }\end{array}$ & $<=1$ hour & $<=1$ hour \\
\hline FM & $\begin{array}{l}0,80 \text { (from FM } \\
\text { table) }\end{array}$ & $\begin{array}{l}0,80 \text { (from FM } \\
\text { table) }\end{array}$ \\
\hline $\begin{array}{l}\text { Coupling } \\
\text { Type }\end{array}$ & Fair & Fair \\
\hline $\mathrm{CM}$ & $\begin{array}{l}0,95 \text { (from } \mathrm{CM} \\
\text { table) }\end{array}$ & $\begin{array}{l}0,95 \text { (from } \mathrm{CM} \\
\text { table) }\end{array}$ \\
\hline RWL & 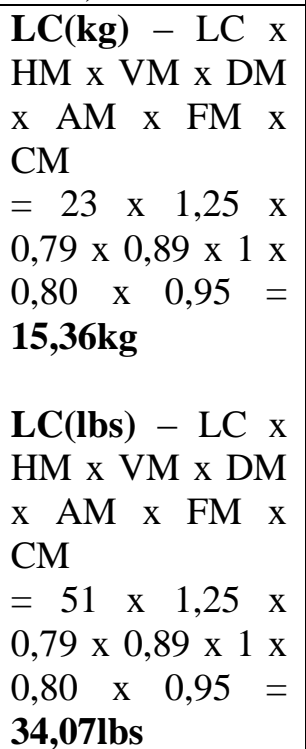 & 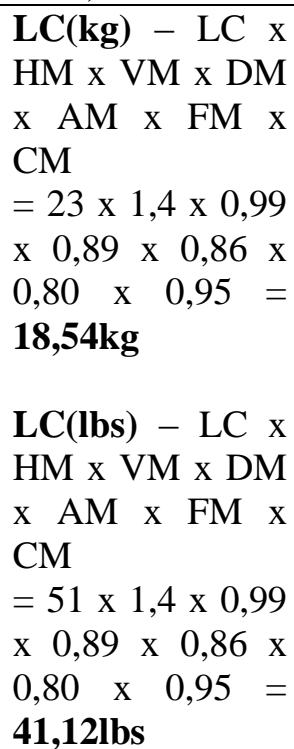 \\
\hline $\begin{array}{l}\text { Berat } \\
\text { Beban }\end{array}$ & $15 \mathrm{~kg} / 33 \mathrm{lbs}$ & $15 \mathrm{~kg} / 33 \mathrm{lbs}$ \\
\hline LI & $\begin{array}{l}\text { LC(kg) - Berat } \\
\text { Beban/RWL = } \\
15 \mathrm{~kg} / 15,36=\mathbf{0 , 9} \\
\mathbf{L C}(\mathbf{l b s})-\text { Berat } \\
\text { Beban/RWL = } \\
33 / 34,07=\mathbf{0 , 9}\end{array}$ & $\begin{array}{l}\mathbf{L C}(\mathbf{k g})-\text { Berat } \\
\text { Beban/RWL = } \\
15 \mathrm{~kg} / 18,54=\mathbf{0 , 8} \\
\mathbf{L C}(\mathbf{l b s})-\text { Berat } \\
\text { Beban/RWL = } \\
33 / 34,07=\mathbf{0 , 8}\end{array}$ \\
\hline
\end{tabular}

Dari perhitungan yang ada pada tabel diatas didapatkan nilai RWL origin = $15,36 \mathrm{~kg} / 34,07 \mathrm{lbs}$ dan nilai $\mathrm{RWL}$ destination $=$ $18,54 \mathrm{~kg} / 41,12 \mathrm{lbs}$. Setelah diketahui nilai RWLnya maka kita dapat menghitung nilai LInya dengan membagi berat beban dengan 
nilai RWLnya, dan didapatkan hasil LI origin = 0,9 dan LI destination $=0,8$.

Dari hasil Lifting Index tersebut dapat disimpulkan bahwa tingkat resiko pekerjaan ini rendah, karena nilai Lifting Index kurang dari 1 (LI < 1). Pada pekerjaan ini tidak ada masalah dengan pekerjaan angkat-angkut. Berat dus air mineral yang diangkat oleh pekerja tidak melebihi RWL, sehingga tidak diperlukan perbaikan terhadap pekerjaan, tetapi harus terus mendapatkan perhatian agar nilai LInya dapat tetap dipertahankan sehingga aktivitas tersebut tidak mengandung resiko cedera tulang belakang.

\section{SIMPULAN DAN SARAN}

\section{Simpulan}

Beban kerja maksimum yang mampu dilakukan pekerja mengangkat atau memindahkan dus air mineral memiliki nilai LI origin 0,9 dan destinasi 0,8. Karena kedua nilai ini $<1$ maka masuk dalam tingkat resiko rendah. Sehingga dapat disimpulkan bahwa tidak ada masalah dengan pekerjaan mengangkat tersebut dan tidak diperlukan perbaikan terhadap pekerjaan tersebut.

\section{Saran}

Saran yang dapat diberikan yaitu agar nilai LI tersebut dapat dipertahankan $<1$.

\section{REFERENSI}

1. Nurmianto, E. Ergonomi Konsep Dasar dan Aplikasinya (Edisi kedua). Surabaya. Guna Widya. 2004.

2. Waters, T. R.; Anderson, V. P.; Garg, A. Application Manual for the Revised NIOSH Lifting Equation. Cincinnati. US Department of Health and Human Service. 1994.

3. Waters, T. S. \& Putz Anderson, V. Revised NIOSH Lifting Equation. New York. Marcel Dekker Inc. 1996.

4. Waters, T. R.; Anderson, V. P.; Garg, A., Fine, J. Revised NIOSH Equation for the Design and Evaluation of Manual Lifting Task. National Institute for Occupational Safety and Health. Cincinnati. 1993.

5. Tarwaka; Bakri, S. H. A.; Sudiajeng, L. Ergonomi, untuk Keselamatan, Kesehatan Kerja dan Produktivitas. Surakarta. UNIBA Press. 2004.

6. Tarwaka. Ergonomi Industri Dasar-Dasar Pengetahuan Ergonomi dan Aplikasi di Tempat Kerja. Surakarta. Harapan Press. 2010. 